\title{
A Study of Clinical Profile of Recurrent Tuberculosis in People Living with $\mathrm{HIV} / \mathrm{AIDS}$
}

Rajneesh Thakur* and Sashindran VK

AFMC Medicine, Department of Medicine, AFMC, Pune, India

\begin{abstract}
Background: Tuberculosis (TB) is a common infection in an endemic country like India and a major cause of mortality in people living with HIVIAIDS (PLHA). Primary objectives: To study the prevalence of recurrent TB in patients of HIV/TB coinfection. Secondary objective: 1) To study the clinical profile of recurrent TB cases. 2) To study the factors associated with recurrence of TB in patients of HIV/TB co-infection.

Materials and method: This retrospective observational study was conducted at a tertiary care hospital in Pune, India between November 2014 to August 2016 in which case records of 185 patients with known HIV/TB co-infection were studied for the clinical and immunological status during initial presentation and during recurrence TB.

Results: The prevalence of recurrent TB in this study was $34.59 \%$ (64 subjects). The average time to recurrence was 34.27 months. Occurrence of disseminated or sputum negative pulmonary TB during initial TB illness was significantly associated with recurrence of TB (RR of $0.325(0.18-0.58)$ and RR of 2.45 (1.68-3.57) respectively. The 6 -month anti-tuberculosis therapy (ATT) regimen was significantly associated with recurrence of TB as compared to 9 month of ATT ( $p$ value $<0.001$, OR 0.0029 ).

Conclusion: Recurrent TB is a significant clinical problem in HIV positive patients. Male sex, sputum negative pulmonary TB or disseminated infection at the first instance of TB, a high Mantoux reading at initial TB presentation ( $\geq$ $20 \mathrm{~mm}$ ) and shorter duration of ATT ( 6 months versus 9 months) are all significant risk factors for recurrence.
\end{abstract}

Keywords: Tuberculosis; Anti-tuberculosis therapy; Anti-retroviral therapy; Recurrence

\section{Introduction}

The global impact of the dual epidemics of TB and HIV continues to be a major public health challenge. The World Health Organization (WHO) Global Status Report 2016, reports 10.4 million new cases of TB in 2015 of whom 11\% were HIV-infected. This is an increase in the number of new TB cases from 9.2 million in 2014. Sixty percent of the new TB cases are reported from India, Indonesia, China, Nigeria, Pakistan and South Africa. There has also been an increase in the number of multi-drug resistant TB (MDR-TB) cases, the number standing at 480,000 in 2015 [1]. TB-related mortality in 2015 was 1.4 million. An additional 0.4 million TB deaths occurred in people living with HIV/AIDS (PLHA). Despite these gloomy results, there has been a $66 \%$ decline in new HIV infections in India since 2000 mainly because of rapid roll-out and scaling up of anti-retroviral therapy (ART) coverage in India. Widespread availability of ART has led to decreased HIV transmission [2]. HIV prevalence in India has decreased from $0.41 \%$ in 2001 to $0.26 \%$ in 2015 [3].

HIV-TB co-infection forms a deadly combination with higher pill burden, complicated drug regimens, higher chances of failure and recurrent disease. TB can develop at any $\mathrm{CD} 4$ cell count; however, extrapulmonary and disseminated forms of the disease are more common as immunodeficiency increases. In HIV-infected patients, the risk of recurrent disease is also much higher, and various studies have demonstrated that this can be due to treatment failure, emergence of drug resistance during therapy, or re-infection with a new strain of Mycobacterium tuberculosis [4-6].

The aim of this study was to find out the burden of recurrent TB in a population with high prevalence of HIV-TB co-infection. We estimated the prevalence rate and also studied the clinical profile of such patients. We also looked at the factors which could predict recurrence.

\section{Materials and Methods}

\section{Study population and setting}

The study was conducted at a tertiary care hospital in Pune, Maharashtra, India over a period of 2 years from November 2014-November 2016. It was a retrospective observational study in which records of an HIV/TB co-infected cohort was studied. Institutional ethics committee approval was taken and permission of the data manager was taken at the commencement of the study (IEC/ November 2014 dated 1 December, 2014). Identity of the study subjects was kept confidential and there were no therapeutic interventions. With the assumption of $50 \%$ prevalence of tuberculosis (including latent TB), the calculated sample size was 185 cases with an a value of $5 \%$. A standardized proforma was used to collect the data. HIV infection was diagnosed on the basis of enzyme-linked immunosorbent assay and cases were started on ART as per the existing national guidelines. Tuberculosis was suspected on the basis of clinical, microbiological, radiographic features and response to ATT (anti-tuberculosis treatment).

WHO case definitions for diagnosis of various forms of TB were used in this study [7]. Immune reconstitution inflammatory syndrome

*Corresponding author: Rajneesh Thakur, Assistant Professor, AFMC Medicine, Department of Medicine, AFMC, Pune, Maharashtra 411040, India; Tel: +918554828920; E-mail: rajneesh2207@gmail.com

Received March 05, 2018; Accepted April 03, 2018; Published April 10, 2018

Citation: Thakur R, Sashindran VK (2018) A Study of Clinical Profile of Recurrent Tuberculosis in People Living with HIVIAIDS. J AIDS Clin Res 9: 764. doi: 10.4172/2155-6113.1000764

Copyright: ( 2018 Thakur R, et al. This is an open-access article distributed under the terms of the Creative Commons Attribution License, which permits unrestricted use, distribution, and reproduction in any medium, provided the original author and source are credited. 
(IRIS) was diagnosed on basis of International Network for the study of HIV-associated IRIS (INSHI) definition [8]. Only subjects in the HIV/TB cohort who had been followed for a minimum of 5 years after initiation of ART were included in the study. Subjects with ATT default, suboptimal adherence to ART, history of alcohol dependence or substance abuse behavior were excluded from the study. The prevalence of recurrence of TB was estimated. Initial presentation of TB, pattern of recurrence, clinical and immunological status at initial presentation and again at the time of recurrence was studied. Occurrence of IRIS was also looked into.

\section{Statistical analysis}

Data analysis was done by SPSS software version 22. Means and standard deviations were calculated where applicable. Chi-square test and Fischer exact test were used to test statistical association. Mann Whitney $\mathrm{U}$ test was used to test statistical association of weight with recurrence of TB. ROC curve was plotted to look for predictive value of Mantoux for TB recurrence.

\section{Results}

A total of 185 subjects with HIV/TB co- infection were enrolled in this study. Out of 185 patients, 64 (34.59\%) patients had recurrence of tuberculosis, giving a prevalence rate of $34.59 \%$.

\section{Baseline characteristics during initial TB}

The number of males was higher as compared to females (M:F166:19). The mean age was $38.7 \pm 8.5$ years (and median age was 38 years and range 18-72 years). HIV positive patient presented most commonly with disseminated TB (DTB) in 72 (38.91\%) and sputum negative TB in $56(30.27 \%)$ cases.

Fever was the most common presenting symptom in 159 (85.94\%) patients followed by weight loss in $58(31.35 \%)$ cases. The most common clinical sign during initial TB was lymphadenopathy which was seen in 87 cases $(47.03 \%)$, followed by hepatosplenomegaly in 43 cases $(23.24 \%)$.

Weight record at the time of initial TB disease was available for 181 subjects. Mean weight was $53.77 \pm 9.16 \mathrm{~kg}$ (and median weight of $54 \mathrm{~kg}$, range 23-80 kg, Q1: 48 and Q3: $54 \mathrm{~kg}$ ).

Mantoux test results were available for 108 patients during initial TB. Mean induration seen on Mantoux test was $10.02 \pm 5.37 \mathrm{~mm}$ (and median $10 \mathrm{~mm}, \mathrm{Q} 1: 6 \mathrm{~mm}$ and Q3: $10 \mathrm{~mm}$ with a range of 0-32 $\mathrm{mm}$ ). During initial TB, various ATT regimen used were: $2 \mathrm{EHRZ}+7 \mathrm{HR}$ in 96 cases $(51.89 \%), 2 \mathrm{EHRZ}+4 \mathrm{HR}$ in 72 cases $(38.91 \%), 2 \mathrm{EHRZ}+10 \mathrm{HR}$ in $9(4.86 \%), 2 \mathrm{EHRZ}+6 \mathrm{HR}$ in $3(1.62 \%), 2 \mathrm{EHRZ}+9 \mathrm{HR}$ in $2(1.08 \%)$, $3 \mathrm{EHRZ}+6 \mathrm{HR}, 3 \mathrm{EHRZ}+9 \mathrm{HR}$ and $4 \mathrm{EHRZ}+7 \mathrm{HR}$ in 1 cases (0.54\%) each.

(2/3/4 - Intensive phase with EHRZ; + 4/5/6/9/7/10 - continuation phase with HR; $\mathrm{H}=$ Isoniazid; $\mathrm{R}=$ Rifampicin; $\mathrm{E}=$ Ethambutol; $\mathrm{Z}=$ Pyrazinamide; $\mathrm{S}=$ Streptomycin)

It was noted that a longer duration of ATT was associated with lesser recurrence of TB (OR for recurrence of TB with a $6 \mathrm{~m}$ ATT was 0.0029 as compared to $9 \mathrm{~m}$ ATT, $\mathrm{p}<0.001)$.

IRIS was noted in 8 cases (4.32\%) and 3 cases (37.5\%) had it within 3 months of initiation of ART with a range of 1 month to 5 month. The mean CD4 cell count of these cases was 127.7/ul with a range of 32310 cells/ $\mu \mathrm{l}$. 6 cases $(75 \%)$ were on ZLE ( $\mathrm{Z}=$ Zidovudine, $\mathrm{L}=$ Lamivudine and $\mathrm{E}=$ Efavirenz) based ART and 1 (12.5\%) each was on ZLN/ZSE ( $\mathrm{N}=$ Nevirapine and $\mathrm{S}=$ Stavudine) based therapy. All the patients were taking $2 \mathrm{EHRZ}+4 \mathrm{HR}$ based ATT.

\section{Characteristics of recurrent TB}

A male preponderance was seen in the members of the HIV/TB cohort who had recurrence of TB over the 5 year follow up (M:F ratio of 52:12). The sex distribution was considered statistically significant for males ( $\mathrm{p}$ value of 0.009 ).

Average time to recurrence of TB was 34.27 months with a minimum of 5 months and a maximum of 141 months (and a median duration of 34 months).

The type of tuberculous disease during recurrence was disseminated TB in 25 cases $(39.1 \%)$ and sputum negative pulmonary TB in 25 cases (39.1\%) as shown in Table 1 . Presenting symptoms were fever in 57 cases $(89.1 \%)$ and weight loss in 12 cases $(18.2 \%)$ and the commonest findings were pallor in 24 cases (37.50\%) followed by lymphadenopathy in 21 cases $(32.81 \%)$.

Weight records were available for 63 cases at the time of recurrence of TB. Mean weight was $52.10 \pm 11.11 \mathrm{~kg}$ (and median weight of $52 \mathrm{~kg}$, range 26-80 kg, Q1: 45 and Q3: $52 \mathrm{~kg}$ ).

Cases with recurrence of $\mathrm{TB}$ were stratified according to $\mathrm{CD} 4$ count recorded during diagnosis of the initial TB illness. It was seen that CD4 count at the time of initial TB illness had no bearing on recurrence of TB (p value 0.064). This is shown in Table 2.

No episode of IRIS was seen during the recurrence of TB.

\section{Predictors of recurrence}

A subgroup analysis was done between subjects who had recurrence of $\mathrm{TB}$ and those who did not in order to identify factors that could predict recurrence of $\mathrm{TB}$.

Male sex was associated with recurrence ( $\mathrm{p}$ value 0.009 ).

The CD4 count at the time of initial TB illness did not have any bearing on recurrence of TB ( $p$ value 0.064 ).

\begin{tabular}{|l|c|c|}
\hline Pattern & Index TB $\mathbf{n}(\%)$ & Recurrent TB $\mathbf{~ ( \% ) ~}$ \\
\hline Abdominal & $14(7.56)$ & $1(1.6)$ \\
\hline Bone & $1(0.54)$ & $1(1.6)$ \\
\hline CNS & $3(1.62)$ & $1(1.6)$ \\
\hline DTB & $72(38.91)$ & $25(39.1)$ \\
\hline Pleural TB & $9(4.86)$ & $4(6.3)$ \\
\hline LN TB & $15(8.10)$ & $4(6.3)$ \\
\hline Miliary TB & $4(2.16)$ & 0 \\
\hline Potts spine & $3(1.62)$ & $2(3.1)$ \\
\hline PTB pos & $8(4.32)$ & $1(1.6)$ \\
\hline PTB neg & $56(30.27)$ & $25(39.1)$ \\
\hline Total & 185 & 64 \\
\hline
\end{tabular}

CNS: Central Nervous System; DTB: Disseminated TB; LN: Tubercula Lymphadenitis; PTB: Pos-Sputum Smear Positive Pulmonary TB; PTB: NegSputum Smear Negative Pulmonary TB

Table 1: Pattern of TB.

\begin{tabular}{|l|c|c|c|}
\hline & \multicolumn{3}{|c|}{ Initial TB (n=176) } \\
\hline CD4 (cells/ $\boldsymbol{\mu l})$ & Rec TB & Non Rec & Total \\
\hline $\mathbf{5 0}$ & $7(12.28 \%)$ & $24(20.17 \%)$ & $31(17.61 \%)$ \\
\hline $\mathbf{5 1 - 1 5 0}$ & $20(35.09 \%)$ & $49(41.18 \%)$ & $69(39.20 \%)$ \\
\hline $\mathbf{1 5 1 - 3 0 0}$ & $18(31.58 \%)$ & $37(31.09 \%)$ & $55(31.25 \%)$ \\
\hline$>\mathbf{3 0 0}$ & $12(21.05 \%)$ & $9(7.56 \%)$ & $21(11.93 \%)$ \\
\hline Total & $57(32.38 \%)$ & $119(67.61 \%)$ & $176(100 \%)$ \\
\hline p-value & \multicolumn{2}{|c|}{0.064} & \\
\hline
\end{tabular}

Table 2: CD4 results during various stages of HIV/TB co-infection. 
In our study we found that the presence of smear negative pulmonary TB during the initial TB illness was associated with recurrence (RR $2.45(1.68-3.57)$ and the results were statistically significant $(\mathrm{p}<0.001)$. Disseminated TB had a RR of $0.325(0.18-0.58)$ for recurrence of TB and the results were again statistically significant $(\mathrm{p}<0.001)$.

The impact of body weight at the time of initial TB on recurrence was studied. Despite the fact the people who had recurrence of TB had a lower mean body weight during initial TB illness (mean of 52.11 $\pm 10.47 \mathrm{~kg}$ in recurrent group and a mean of $54.62 \pm 8.34 \mathrm{~kg}$ in the nonrecurrent group); this was not statistically significant (Mann-Whitney $\mathrm{U}$ test p-value 0.079 ).

We next looked at whether Mantoux reactivity at the time of initial TB workup had any bearing on TB recurrence. It was seen that cases with a higher Mantoux reaction $(\geq 20) \mathrm{mm}$ during the initial episode were likely to have recurrence $(\mathrm{n}=4, \mathrm{p}<0.0010)$. An ROC curve was plotted and it was found that a Mantoux reading of $\geq 8 \mathrm{~mm}$ was associated with recurrence with a sensitivity of $93.3 \%$ (95\% CI 77.999.0 ) and specificity of $55.1 \%$ (95\% CI 43.4-66.4) with +LR 2.08 and -LR 0.12.

We then looked at the impact of duration of ATT on recurrence of TB. Most of the subjects who had recurrent TB had been exhibited a shorter ATT regimen in comparison to those who did not have recurrence: $62(96.88 \%)$ of those with recurrence had been exhibited 6 month of ATT while 95 (78.51\%) of those who had no recurrence had been treated with 9 months ATT regimen. These results were significant with a $\mathrm{p}$ value of $<0.001$ with shorter duration of treatment being associated with higher chances of recurrence (OR 0.0029).

\section{Discussion}

Tuberculosis is the leading cause of death in people with HIV/AIDS [9]. The chances of recurrence of TB in HIV patients are also higher. In a study from South India, Narayanan et al. [4] found a recurrence rate of $14 \% ; 22(88 \%)$ of 25 cases were due to re- infection with a different strain of Mycobacterium tuberculosis [4]. Glynn et al. [5] reported on rates of recurrent tuberculosis in South Africa and found recurrence rates of 24.4 cases per 100 person-years at risk for initially HIV-infected miners following their index episode and 4.7 cases per 100 person-years at risk among those who were HIV-negative at the index episode. In another study done in Brazil, 37.7\% of recurrent TB patients were HIV positive [6]. Our study showed a greater concordance with that from Brazil than other studies.

The sex ratio seen in our study showed a male predominance with 166 males and 19 females. These results are in concordance with the WHO report wherein there is a male predominance in the incident cases of HIV [1]. In various other studies similar results were seen $[10,11]$. Male gender was associated with higher chances of recurrence of TB in our study but the results could have been confounded by a selection bias because of a higher number of male patients attending our clinic. HIV affects people in all age groups and the prevalence of $\mathrm{HIV}$ is highest in the age group of $18-40$ years. In our study also $78.37 \%$ cases were in the economically productive age group. The recurrence rate was also highest in the same age group. Similar demographic findings have been reported from the studies in South Africa and India [10-12]. Comparative results of demographic characteristics are shown in Table 3.

The mean time to recurrence was 34.27 months (minimum of 5 months and a maximum of 141 months and a median duration of 34 months). The timing to recurrence of TB was much longer as compared to that reported in other studies [4-6,13-15]. Comparative results of various studies are shown in Table 4 . This could have been because of a better follow up of the patients at this centre and possibly better compliance to medication. Another factor can be the co-location of ART and TB treatment centres which leads to early detection and management of TB in PLHA. As this study was conducted in an urban centre, with better facilities of transportation as well as better diagnostic and therapeutic options, compliance to therapy is likely to have been better. In studies done in Africa, distance from health facility has been shown to be associated with poor drug compliance and recurrence of TB $[10,16,17]$.

Patients were also studied with respect to the organ system involvement by Mycobacterium tuberculosis. Studies have shown varying results as far as the organ system involvement in $\mathrm{TB}$ is concerned [12,18-20]. In our study we found out that patients presented most commonly with DTB $72(38.91 \%)$ and sputum negative $\mathrm{TB}$ in $56(30.27 \%)$ cases during initial TB and similarly at the time of recurrence of $\mathrm{TB}$, most patients were likely to present as disseminated TB 25 (39.1\%) and sputum negative 25 (39.1\%) cases. The results of our study are in agreement with other studies $[12,18]$. We also found that the presence of smear negative pulmonary TB during the initial TB illness was significantly associated with recurrence of $\mathrm{TB}$.

Fever and weight loss were the commonest symptoms during both initial TB illness and recurrence $(85.94 \%, 31.35 \%$ and $89.1 \%, 18.2 \%$, respectively). Kamath et al. [12] and Patel et al. [21] also found fever to be the commonest symptom in PLHA contracting TB. This study shows that fever and weight loss in a patient with HIV infection should lead to consideration of TB as a possible diagnosis. However the duration of fever as a predictor of TB diagnosis was not studied.

The commonest clinical findings during initial TB illness were lymphadenopathy $(\mathrm{n}=87 ; 47.03 \%)$ followed by hepatosplenomegaly $(n=43 ; 23.34 \%)$. During recurrence of TB the commonest finding was pallor $(n=24 ; 37.50 \%)$ and lymphadenopathy $(n=21 ; 32.81 \%)$. Lymphadenopathy has been reported as a common clinical finding by Gupta [22], Hewlett et al. [23] and Hochedez et al. [24].

$\mathrm{TB}$ can occur at any $\mathrm{CD} 4$ count and the risk keeps on increasing with

\begin{tabular}{|l|c|c|c|}
\hline & Mphothulo et al. [10] & Gautam et al. [11] & Kamath et al. [12] \\
\hline M:F & $2.2: 1$ & $1.1: 1$ & $3.04: 1$ \\
\hline Sexually active age group (\%) & 54.5 & 71.43 & 61.3 \\
\hline Heterosexual mode (\%) & - & 94.03 & $78.1: 1$ \\
\hline
\end{tabular}

Table 3: Demographic characteristics.

\begin{tabular}{|l|c|c|c|}
\hline & Unis et al. [6] & Petit et al. [13] & Luzze et al. [15] \\
\hline Median time to recurrence(months) & 18.3 & 13.7 & 9.9 \\
\hline
\end{tabular}

Table 4: Time to recurrence. 
progressive immune paralysis. As CD4 count declines, presentation also becomes more atypical and protean [25-28]. In our study, we found that CD4 count at HIV diagnosis was not significantly associated with recurrent disease ( $p$ value 0.311 ) and that CD4 count during initial TB could not predict recurrence ( $\mathrm{p}$ value 0.064 ).

One possible explanation for this could be the high prevalence of TB in India with high rates of TB transmission across the population irrespective of CD4 counts. Another important finding seen in this study was that as compared to baseline CD4 and CD4 count during initial TB, proportion of cases with CD4 count $>300$ cells/ $\mu$ l was higher during the time of recurrence of $\mathrm{TB}$ which could mean that recurrence of TB may not necessarily imply treatment failure. It could be due to unmasking IRIS secondary to immune restitution by effective ART.

Weight loss is a common feature in tuberculosis infection. In our study we compared weight characteristics of patients having recurrence of $\mathrm{TB}$ and those not having recurrence. Though, the median weight of cases with recurrent disease was lower than those who did not have recurrence, the results were not significant ( $p$-value 0.079). The results of our study were different from the study of Khan et al. [29], in which it was shown that relapse risk was high among persons who were underweight at diagnosis $(19.1$ vs. $4.8 \%$; $\mathrm{p}<0.001)$ or who had a body mass index of less than $18.5 \mathrm{~kg} / \mathrm{m}^{2}$ (19.5 vs. $5.8 \%$; $\mathrm{p}<0.001$ ) [29]. In a study done in Africa, it was shown that low weight or BMI was associated with a higher incidence of $\mathrm{TB}$; however, this study was not done on HIV/TB co-infected population [10]. We were not able to calculate BMI since height was not recorded in many of the case records.

The role of tuberculin skin testing (TST) has remained controversial in diagnosis of TB and results are further confounded by HIV infection. Mantoux test has been shown to have varying sensitivity and specificity. We did a subgroup analysis of Mantoux reactivity at the time of evaluation for initial TB illness and compared the values between those who had TB recurrence and those that did not. Cases with a higher Mantoux reaction $\geq 20 \mathrm{~mm}$ during the initial episode, were likely to have recurrence and this result was statistically significant $(\mathrm{p}<0.001)$. Using the ROC curve, it was found that Mantoux reading of $\geq 8 \mathrm{~mm}$ was associated with recurrence with a sensitivity of $93.3 \%$ (95\% CI 77.9-99.0) and specificity of 55.1\% (95\% CI 43.4-66.4). In a study done in Tanzania, the sensitivity of the TST among HIV-infected patients was $64.3 \%$ at a cut-off value of $10 \mathrm{~mm}$ and $71.2 \%$ at a cut-off value of $5 \mathrm{~mm}$ [30]. A wide variation has been reported in tuberculin test positivity in other studies [19,21]. However, none of these studies were done to predict the rate of recurrence.

Combination ATT is the recommended form of treatment for TB. Different countries of the world has adopted the WHO recommended directly observed treatment short-course (DOTS) programme for the treatment of TB. In this study we looked for the effect of ATT duration on TB recurrence. It was seen that the cases who received 9 months of ATT during the initial episode of TB were less likely to have recurrence compared to patients who received standard 6 months of ATT (OR 0.0029, p<0.001). In a study comparing 6 months vs. 9 months treatment it was shown that a 9 months regimen resulted in a significantly lower bacteriological recurrence rate compared with a 6 months thrice-weekly regimen $(15$ vs. $7 \%$; $p<0.05)$ [31]. In another study done in Taiwan, it was shown that the risk of TB recurrence in HIV-infected patients can be further reduced by extending anti-TB treatment to 9-12.5 months [32]. These findings are in concordance with scientific evidence of treating TB in PLHA with daily ATT and a longer duration of therapy.
Paradoxical TB-IRIS is relatively common in patients starting ART while on TB treatment ( $8 \%-43 \%)$. In a meta-analysis, a pooled estimate of incidence of IRIS of $15.7 \%$, with a case fatality rate of $3.2 \%$ was provided [33]. In a series from southern India TB-IRIS was reported in $7.6 \%$ of patients [34]. In another study from India, incidence of $7.5 \%$ for paradoxical TB-IRIS and 3\% for ART-associated TB was shown in a retrospective study [35]. In the present study we found that IRIS occurred in 8 cases giving a prevalence rate of $4.32 \%$. Three (37.5\%) patients had it within 3 months of initiation of ATT with range of 1 month to 5 months, the results of which are similar to those seen by Meintjes $\mathrm{G}$ et al., who found out that most of the cases occur within 3 months of initiation of ATT [8].

All patients in whom IRIS was noted had disseminated TB. The most consistent risk factors for paradoxical TB-IRIS are low CD4 cell count at start of ART (especially CD 4 cell counts $<100$ cells/ $\mu$ l), disseminated or extrapulmonary TB and a short interval between starting TB treatment and ART, particularly within the first 2 months of TB treatment [36-39]. We too noted the relationship between disseminated TB and increased incidence of IRIS. However, we did not study the effect of CD4 count and viral load on occurrence of IRIS.

This study enrolled 185 cases from a HIV-TB cohort who had been followed up for $\geq 5$ years. The clinical findings of the cases have been well described. In the subgroup analysis we were able to identify various factors which could predict recurrence of TB.

\section{Limitations}

The limitation of the study is that we could not differentiate between relapse and re- infection which requires DNA finger printing of the MTB. Retrospective study design is also another limitation of this study.

\section{Conclusion}

HIV-TB is responsible for high mortality and morbidity among PLHA. Recurrence of TB due to reactivation or re-infection is common amongst PLHA, more so in high TB burden regions. This 5 years follow up cohort study of HIV-TB shed some interesting information. The commonest clinical findings in HIV-TB are fever, weight loss and lymphadenopathy. There are no clinical findings which can be used as definite predictors of TB recurrence. However, incidence of sputum negative pulmonary TB during initial TB illness is significantly associated with recurrence. A Mantoux reading of $\geq 8 \mathrm{~mm}$ is a good marker for risk of TB recurrence. A longer ATT regimen $(9$ months vs. 6 months) reduces the risk of recurrence of TB in PLHA.

\section{References}

1. World Health Organization (2016) Global tuberculosis report 2016. World Health Organization, Geneva.

2. United Nations Programme on HIVIAIDS (2016) Global AIDS update 2016 United Nations Programme on HIVIAIDS (UNAIDS), Switzerland.

3. National AIDS Control Organisation (2016) National Framework for HIV TB in India 2013, Integrated HIVTB module 2016, NACO-CTD, MoHFW GOI and Vihaan program guidelines.

4. Narayanan S, Swaminathan S, Supply P, Shanmugam S, Narendran G, et al. (2010) Impact of HIV infection on the recurrence of tuberculosis in South India. $\mathrm{J}$ Infect Dis 201: 691-703.

5. Glynn JR, Murray J, Bester A, Nelson G, Shearer S, et al. (2010) High rates of recurrence in HIV-infected and HIV-uninfected patients with tuberculosis. J Infect Dis 201: 704-711.

6. Unis G, Ribeiro AW, Esteves LS, Spies FS, Picon PD, et al. (2014) Tuberculosis recurrence in a high incidence setting for HIV and tuberculosis in Brazil. BMC Infect Dis 14: 548. 
Citation: Thakur R, Sashindran VK (2018) A Study of Clinical Profile of Recurrent Tuberculosis in People Living with HIVIAIDS. J AIDS Clin Res 9: 764. doi: $10.4172 / 2155-6113.1000764$

7. World Health Organization (2013) Definitions and reporting framework for tuberculosis - 2013 revision. World Health Organization, Geneva.

8. Meintjes G, Lawn SD, Scano F, Maartens G, French MA, et al. (2008) Tuberculosis-associated immune reconstitution inflammatory syndrome: Case definitions for use in resource-limited settings. Lancet Infect Dis 8: 516-523.

9. Richard EC, Gavin JC (2010) Recurrent tuberculosis. Relapse, reinfection and HIV. J Infect Dis 201: 653-655.

10. Mphothulo N, Pengpid S, Peltzer K (2012) Factors associated with tuberculosis reinfection and treatment failure in Taung sub-district, South Africa. Ethno Med 6: $23-30$

11. Gautam L, Deshpande JD, Somasundaram KV (2014) Prevalence of HIV-TB co-infection, clinical profile and CD4 count of HIV patients attending ART centre of Ahmednagar, Maharashtra. Int J Med Sci Public Health 3: 1105-1109.

12. Kamath R, Sharma V, Pattanshetty S, Hegde MB, Chandrasekaran V (2013) HIV-TB co-infection: Clinico-epidemiological determinants at an antiretroviral therapy center in Southern India. Lung India 30: 302-306.

13. Pettit A, Kaltenbach L, Maruri F, Cummins J, Smith T, et al. (2011) Chronic lung disease and HIV infection are risk factors for recurrent tuberculosis in a lowincidence setting. Int J Tuberc Lung Dis 15: 906-911.

14. Nunn A, Phillips P, Mitchison D (2010) Timing of relapse in short-course chemotherapy trials for tuberculosis. Int J Tuberc Lung Dis 14: 241-242.

15. Luzze H, Johnson DF, Dickman K, Mayanja-Kizza H, Okwera A, et al. (2013) Relapse more common than reinfection in recurrent tuberculosis 1-2 years post treatment in urban Uganda. Int J Tuberc Lung Dis 17: 361-367.

16. Marx FM, Dunbar R, Hesseling AC, Enarson DA, Fielding K, et al. (2012) Increased risk of default among previously treated tuberculosis cases in the Western Cape Province, South Africa. Int J Tuberc Lung Dis 16:1059-1065.

17. Amuha MG, Kutyabami P, Kitutu FE, Odoi-Adome R, Kalyango JN (2009) Nonadherence to anti-TB drugs among TB/HIV co-infected patients in Mbarara Hospital Uganda: Prevalence and associated factors. Afr Health Sci 9: 8-15.

18. Lee MP, Chan JW, Ng KK, Li PC (2000) Clinical manifestations of tuberculosis in HIV-infected patients. Respirology 5: 423-426.

19. Mohanty KC, Sundrani RM, Nair S (1993) HIV infection in patients with respiratory disease. Indian J Tuberc 40.

20. Deivanayagam CN, Rajasekaran S, Senthilnathan V, Krishnarajsekhar R Raja K, et al. (2001) Clinico-radiological spectrum of tuberculosis among HIV seropositives: A Tambram study. Cough 1367: 85-4323.

21. Patel AK, Thakrar SJ, Ghanchi FD (2011) Clinical and laboratory profile of patients with TB/HIV co-infection: A case series of 50 patients. Lung India 28 : 93-96.

22. Gupta PR (2004) Difficulties in managing lymph node tuberculosis. Lung India 21: $50-53$.

23. Hewlett Jr D, Duncanson FP, Jagadha V, Lieberman J, Lenox TH, et al (1988) Lymphadenopathy in an inner-city population consisting principally of intravenous drug abusers with suspected acquired immunodeficiency syndrome. Am J Resp Crit Care Med 137: 1275-1279.

24. Hochedez P, Zeller V, Truffot C, Ansart S, Caumes E, et al. (2003) Lymph-node tuberculosis in patients infected or not with HIV: General characteristics, clinical presentation, microbiological diagnosis and treatment. Pathologie-biologie 51 496-502.

25. Sonnenberg P, Glynn JR, Fielding K, Murray J, Godfrey FP, et al. (2007) How soon after infection with HIV does the risk of tuberculosis start to increase? A retrospective cohort study in South African gold miners. J Infect Dis 191 150-158.

26. Havlir DV, Getahun H, Sanne I, Nunn P (2008) Opportunities and challenges for HIV care in overlapping HIV and TB epidemics. JAMA 300: 423-430.

27. Getahun H, Gunneberg C, Granich R, Nunn P (2010) HIV infection associated tuberculosis: The epidemiology and the response. Clin Infect Dis 50: S201-S207.

28. World Health Organization (2004) Interim policy on collaborative TB/HIV activities. World Health Organization, Geneva.

29. Khan A, Sterling TR, Reves R, Vernon A, Horsburgh CR (2006) Lack of weigh gain and relapse risk in a large tuberculosis treatment trial. Am J Resp Crit Care Med 174: 344-348.

30. Cobelens FG, Egwaga SM, Ginkel T, van Muwinge H, et al. (2006) Tuberculin skin testing in patients with HIV infection: Limited benefit of reduced cut-off values. Clin Infect Dis 43: 634-639.

31. Swaminathan S, Narendran G, Venkatesan P, lliayas S, Santhanakrishnan R et al. (2010) Efficacy of 6 month vs. 9 month intermittent treatment regimens in HIV-infected tuberculosis patients: A randomized clinical study. Am J Resp Crit Care Med 181: 743-751.

32. Wang JY, Sun HY, Wang JT, Hung CC, Yu MC, et al. (2015) Nine to twelve month anti-tuberculosis treatment is associated with a lower recurrence rate than 6-9-month treatment in human immunodeficiency virus-infected patients: $A$ retrospective population-based cohort study in Taiwan. PLoS One 10: e0144136.

33. Muller M, Wandel S, Colebunders R, Attia S, Furrer H, et al. (2010) Immune reconstitution inflammatory syndrome in patients starting antiretroviral therapy for HIV infection: A systematic review and meta-analysis. Lancet Infect Dis 10 251-261.

34. Kumarasamy N, Chaguturu S, Mayer KH, Solomon S, Yepthomi HT, et al (2004) Incidence of immune reconstitution syndrome in HIV/tuberculosis coinfected patients after initiation of generic antiretroviral therapy in India. J AIDS 37: 1574-1576

35. Sharma SK, Dhooria S, Barwad P, Kadhiravan T, Ranjan S, et al. (2010) A study of TB-associated immune reconstitution inflammatory syndrome using the consensus case-definition. Indian J Med Res 131: 804-808.

36. Haddow LJ, Moosa M-YS, Mosam A, Moodley P, Parboosing R, et al. (2012) Incidence, clinical spectrum, risk factors and impact of HIV-associated immune reconstitution inflammatory syndrome in South Africa. PLoS One 7: e40623.

37. Jevtovic D, Salemovic D, Ranin J, Pešic I, Žerjav S, et al. (2005) The prevalence and risk of immune restoration disease in HIV-infected patients treated with highly active antiretroviral therapy. HIV Med 6: 140-143.

38. Ratnam I, Chiu C, Kandala NB, Easterbrook PJ (2006) Incidence and risk factors for immune reconstitution inflammatory syndrome in an ethnically diverse HIV type 1-infected cohort. Clin Infect Dis 42: 418-427.

39. Murdoch DM, Venter WDF, Feldman C, Van Rie A (2008) Incidence and risk factors for the immune reconstitution inflammatory syndrome in HIV patients in South Africa: A prospective study. AIDS 22: 601-610 